\title{
Analyzing the Influence of Gender Stereotypes and Social Norms on Female IT Entrepreneurial Intention in Saudi Arabia
}

\author{
Daniel Chandran \\ University of Technology Sydney, Australia \\ Daniel.Chandran@uts.edu.au
}

\author{
Asma Aleidi \\ University of Technology Sydney, Australia; Princess \\ Nourah bint Abdulrahman University, Saudi Arabia \\ Asma.I.Aleidi@student.uts.edu.au
}

\begin{abstract}
Technological entrepreneurship is continuously growing, and given the lack of women's IT entrepreneurial activities there is a need for further investigation. However, a comprehensive literature review indicates that innovation, technology and female entrepreneurs are rarely discussed in the same context, though each has a vital value for human and economy development. Furthermore, most of the literature on women's entrepreneurship in general and more specifically in Saudi context is focused on non-technological businesses. Therefore, this research in progress examines the relationship between social influence and women's IT entrepreneurial intention and decision-making processes that lead women to become techentrepreneurs in Saudi Arabia. The investigation reveals that understanding entrepreneurial intention as well as its antecedents is a strong predictor to perform behaviors. So, by understanding women's IT entrepreneurial intention, better guidance can be a new driver of entrepreneurial behavior in the technology context.
\end{abstract}

\section{Introduction}

In recent years, technology entrepreneurship has been one of the most important drivers of economic growth, social value, and innovation [16, 17, 20, 41]. In this context, it is widely acknowledged that women's participations in technology entrepreneurship are heavily underrepresented [21, 24, 25, 39, 42]. This phenomenon is more pronounced in a society characterized with a high level of stereotypical gendered expectations toward technology businesses [39] and well-defined gender roles such as Saudi community [5].
Literature suggests that science, technology, and innovation are associated strongly with masculinized culture, which resulted in making such fields less attractive for women. Therefore, this prevailing culture leads to reducing women-related invention and innovation ideas as profitable businesses [13, 24, 25, 39]. In addition, although more women are gaining formal qualifications to enter this field, most in general, remain disadvantaged from technology business opportunities [25, 39, 42]. Specifically, in the Saudi women context, as their knowledge has not yet been transferred into technology businesses [5, 58].

The current literature shows a paucity of research in women's IT entrepreneurship. Specifically, in areas such as Information Systems and female entrepreneurship disciplines, the study of women's IT entrepreneurial behavior is ignored. Scholars suggest that there is a need to understand many aspects of gender relationships in the field of entrepreneurship in general and more specific in technology domain $[2,21]$. Previous studies have attempted to examine different factors to understand women entrepreneurs in the IT context [21, 24, 25, 39]. However, earlier studies examine specific factors and may prevent a comprehensive understanding of female entrepreneurial intention from a technological point of view.

Therefore, given the necessity to enhance women participation in business venturing and the significance of technological entrepreneurship and innovation on socio-economic growth, there is a need for further investigation. This investigation incorporates knowing the status quo, identifying the influential factors and exploring women's probability, their experiences and motivations toward technological entrepreneurship. Particularly, in order to encourage Saudi women tech-entrepreneurs, there is a need for identifying and understanding the factors and decision- making processes that affect 
women's engagement in such businesses. However, literature shows that there is no empirical study to understand female entrepreneurial intention as a predictor to perform IT entrepreneurial behaviors. Furthermore, most of the literature on women's entrepreneurship in general and more specifically in Saudi Arabia is focused on traditional and nontechnological businesses. Consequently, this study is an attempt to fill that void by investigating how influential aspects are linked to IT entrepreneurial intention of women.

Based on the literature review of female entrepreneurship and information systems (IS), the current study aims to examine the influential factors on the intention and decision-making processes that lead women to become tech-entrepreneurs. For the purpose of this study, following research questions have been formulated:

- What role do socio-individual factors play in the entrepreneurial intention to start technological entrepreneurship by women in Saudi context (social norms, attitude, entrepreneurial self-efficacy, and gender stereotypes)?

- What role do technological factors play in the entrepreneurial intention to start technological entrepreneurship by women in Saudi context (personal innovativeness in IT, and related knowledge and experience in technology)?

\section{Literature Review}

\subsection{IT Entrepreneurial Behaviour}

Many authors pointed out that IT entrepreneurs have different antecedents' factors and behavioral characteristics, which are highly related to technology skills and perceptions [12, 16, 17]. However, review of literature shows a very few studies exists in IT entrepreneurship in general and IT entrepreneurial behavior in particular. IT entrepreneurs are expected to have more technological knowledge in addition to higher innovation capabilities and attitudes. Nichols \& Armstrong (2003) describe IT entrepreneurs as individuals, who organize, manage and accept the risk of technological entrepreneurship [44]. In this study, an IT entrepreneur can be viewed as an individual who identifies and exploits opportunities by using technology skills, perceptions, knowledge and experience to create new value through the venture creation process $[16,17,41]$. This definition highlights different antecedents' factors and behavioral characteristics for IT entrepreneurs.
In Information Technology context, there are two ways to study behavior. The first method is to measure behavior directly [e.g.,52]. The second method is to measure behavior indirectly, commonly utilizing behavioral intention, which has been widely adopted in IS literature [e.g., 16, 17, 37]. Also, this method has been widely applied to entrepreneurship in recent years with significant success. Hence, this study uses entrepreneurial intention as a dependent variable to predict a real behavior of women's IT entrepreneurship.

\subsection{Female Entrepreneurship in Saudi Arabia}

Women's entrepreneurship has recently become a topic of interest in Saudi Arabia. Although, women are traditionally restricted to join the economic field for a long time [6], there is a noticeable improvement of women status in this field, driven largely by changing the direction of the Saudi government to support women's empowerment and gender equality. As a case in point, the Ninth Development Plan of Kingdom (2010-2014) marks a new phase in the development by providing greater employment opportunities for women and encouraging them to join the workforce [32]. More recently, Vision 2030, which is a recent policy view of Saudi government marks a new phase in the development by promoting and supporting SME entrepreneurship to create suitable job opportunities for Saudi citizens as well as increasing women's participation in the workforce [54]. The government has launched many entrepreneurship initiatives in an effort to enhance women's role in the labor force and economic sector through entrepreneurship leadership, such as Aramco Entrepreneurship Center, Badir Program from the scientific organization of King Abdulaziz City for Science and Technology (KACST), and Al-Sayedah Khadijah Bint Khuwailid Businesswomen Center, in an effort to support the entrepreneurial culture and develop entrepreneurial leadership among Saudi youth. However, women's participation in these initiatives is nascent and remains as a disadvantaged population with high economic potential.

\section{Theoretical Background and Hypotheses Development}

Two major streams of literature provide the theoretical foundations for this research. The first is the literature on female entrepreneurship, illustrating the role of entrepreneurial intention as well as its antecedents including gender stereotypes and social 
norms factors. The second is the literature on information systems, elaborating the role and importance of two context-specific factors personal innovativeness in IT, and related knowledge and experience in technology, as key drivers of entrepreneurial intention in technological entrepreneurship.

The socio-psychological theories enable researchers to explore the attitudes and other constructs to have a better understanding of intention. Since entrepreneurship represents planned, intentional behavior, it becomes suitable to research using the formal models of intentions [35]. The Theory of Planned Behavior (TPB) by Ajzen (1991) is a broad theory of human behavior, which has been successfully adopted to predict and explain intentions to perform behaviors [4, 9]. Ajzen's theory has also become the most influential and increasingly common framework in entrepreneurial intention literature among others $[9,16,17,19,34,35,38]$.

New businesses are not created accidentally. A considerable amount of literature argues that intention plays a relevant role in decision making to start a new firm and predict entrepreneurial behavior $[4,35,46]$. According to TPB, entrepreneurial intention illustrates the effort that is required from individuals to acquire the entrepreneurial behavior [35]. It is influenced by three antecedents, including, individual's attitude, subjective norms, and perceived behavioral control. This last construct is similar to the construct of perceived self-efficacy [19], which is adopted in this study. Both concepts reflect one's perceived ability to achieve a particular goal or behavior [4, 7].

Many scholars have applied the intentional theory with similar goals in different contexts. From the Information System discipline, the behavioral intention model has been widely adopted in the literature [37]. For instance, Chen, $(2013 ; 2014)$ has adopted the intentional theory to examine empirically IT entrepreneurial behavior and its antecedent factors. He concludes that computer self-efficacy and other factors have a direct and indirect influence on IT entrepreneurial intention [16, 17]. Also, many authors considered intentional theory in their investigation in women's entrepreneurship context [14, 19, 23, 46, 49, 51, 57]. Scholars observe, compared to men, women continue to have lower intentions to start- ups and grow new businesses [19, 23]. Further, Liñan et al, (2010), utilizing Ajzen's theory as a framework for cross-cultural study, have analyzed the different perceptions of both male and female potential entrepreneurs [49]. They conclude that females have lower self-efficacy and entrepreneurial attraction than males, thus leading to lower entrepreneurial intention.

Therefore, it is essential to investigate the female entrepreneurial intention as a predictor to perform IT entrepreneurial behavior as well as its antecedents including entrepreneurial self-efficacy and subjective norms as influential factors on women's IT entrepreneurial intention. According to the literature, in the case of women, these two perceptions can affect to a greater extent the decision of whether or not to start a business $[3,19,30,56,57]$

\subsection{Hypotheses and Research Model}

3.1.1 Pillars of Theory of Planned Behavior: Social Norms, Attitude. Social norms construct is a social perception, which refers to perceived social pressure from people including family, friends and others to perform the entrepreneurial behavior [4, 19]. Individual's attitude refers to the degree to which an individual has a positive or negative personal evaluation about willingness to be an entrepreneur [4, 34]. The theory predicts that greater the positive attitude and positive influence of social norms, greater the intention will be to perform a particular behavior including the entrepreneurial behavior. Therefore, it is proposed that,

Hypothesis 1: Social norms influence positively IT entrepreneurial intention of Saudi women.

Hypothesis 2: Attitude towards entrepreneurship influences positively IT entrepreneurial intention of Saudi women.

3.1.2 Entrepreneurial Self- Efficacy. The individual's self-efficacy concepts interact with behavioral intention and social environment $[11,16]$. Within the field of entrepreneurship, entrepreneurial self-efficacy (ESE) reflects an individual's confidence in his/her ability to be able to succeed as entrepreneurs and perform entrepreneurship roles and tasks successfully $[15,57]$. This construct has also been widely applied in psychology as an individual difference variable. Considerable studies suggest that individuals with higher ESE have higher entrepreneurial intentions [15, 35, 57, 59] among others. Other scholars have specifically focused on whether self-efficacy is a key factor that influences individuals' belief and entrepreneurial decisions [57, 59].

Research on gender aspects has recently focused the attention on self-efficacy belief, perception of abilities and skills from the point of view of society (society's perception of female entrepreneurial skills), and from the perspective of female entrepreneurs themselves. According to the literature, compared to men, women's perception of their entrepreneurial 
skills have been more reduced frequently, regardless of their real skills, particularly in sectors that are seen traditionally as male domains [33, 45, 57]. This perception in turn impacts their entrepreneurial intentions and subsequent lower levels of entrepreneurial behavior [57, 59]. Other authors observed that women tend to perceive themselves and the entrepreneurial environment less desirable for them than for men and these perceptions have negative consequences for female entrepreneurial propensity [36]. Additionally, there is evidence that women are more likely than men to limit their career choice and interests due to their low perception of the necessary skills and capabilities [57].

Similar studies suggest that some women may not utilize opportunities to become entrepreneurs because, compared to men, they tend to have lower entrepreneurial self-efficacy [8, 31]. Recent studies show a positive and significant effect of ESE in women's entrepreneurial intention [7, 8, 14, 57, 59]. Wilson et al. (2007) found empirical evidence that both female adolescents and MBA students program showed strong gender effect and lower rates of ESE and entrepreneurial intention than their men [57]. On the other hand, Palmer et al. (2015) found that the relationship between gender and entrepreneurial intentions was reduced when self-efficacy was considered [46]. Other authors have confirmed that women entrepreneurs with high self-efficacy significantly influence innovative behavior than women entrepreneurs with low self-efficacy [10]. Similarity, Anna et al. (2000) found that self-efficacy has a positive effect on the development of women's entrepreneurial intentions and behavior specifically for non-traditional business including technological entrepreneurship. In the present study, it is possible to consider that women perceptions of themselves play a greater role in the decision to start a business at the IT level. Hence, the following hypothesis is proposed:

Hypothesis 3: Entrepreneurial self-efficacy has a positive effect on IT entrepreneurial intention of Saudi women.

\subsubsection{Gender Role- Stereotyping of} Entrepreneurship. Gender is another fundamental sociocultural dimension that influences entrepreneurial intention. Although gender has been analyzed as biological sex in prior research including IS, and female entrepreneurship literature [3, 19, 53, 59], this study conforms with certain theories [27, 29] as well as previous studies on gender differences in the predictors of intention in entrepreneurship [22, $23,40,48,51]$ that model gender as psychological state and social construct. Gender stereotypes concerning the qualities that associated with each sex often dictate the type of jobs that are considered appropriate for them those jobs become known as predominantly masculine or feminine jobs [27]. Specifically, entrepreneurship has traditionally been as a masculine and male-dominated field $[2,51]$, with fewer women business owners than men [36, 51]. Entrepreneurship scholars have established a relationship between gender stereotypes and entrepreneurial intention. More specifically, gender stereotyping can bring negative impact on women's entrepreneurial intention and could limit their ability to gain social, human, and financial capital $[23,28$, 57]. From a technological entrepreneurship perspective, it is widely acknowledged that women in such business are heavily underrepresented [21, 24, $25,39,42]$. This phenomenon is more pronounced in a society characterized by a high level of stereotypical gendered expectations toward technology businesses [39] and well-defined gender roles such as Saudi community [5]. Specifically, with Saudi culture and society tradition dictating the type of job for women, there is a visible situation of gender difference. Hence, we could observe that gender stereotypes could play an important role in women's decision in IT entrepreneurship as a good career choice. From IS literature, Igbaria et al, (1997) have made similar arguments and they found that gender plays an important role on the IT environment. Men and women may choose different career paths within IT because of their emphasis on different environmental values [3, 30]. Thus, the following hypothesis is proposed:

Hypothesis 4: Gender stereotypes act as a barrier, which affects negatively IT entrepreneurial intentions of Saudi women.

Moreover, gender stereotypes play an important role between the perception of the environment and social norms, and entrepreneurial intention of women entrepreneurs. The negative perception can be an important cause to discourage women for new business creation, since they are highly conditioned by societal norms and the roles ascribed to women [19]. Other authors have examined the role of social norms on female entrepreneurial potential. They found that this construct leads to lower self-efficacy and entrepreneurial attraction for women than men, which in turn affect their entrepreneurial intention [49]. Also, a negative perception of the environment and social norms can instill a fear of failure, which in turn could affect entrepreneurial intention [55]. Therefore, we could observe that the environment and social norms play an important role in women's IT entrepreneurial intention. From IS perspective, this proposition is consistent with Venkatesh \& Morris (2000) assertion that women are strongly 
influenced by subjective norms perceptions of IT and IT usage intentions, and so it is an important concept to be considered [53]. According to the above discussion, the following hypothesis is proposed:

Hypothesis 5: Gender stereotypes affect negatively women's perception of the environment and social norms

3.1.4 Personal Innovativeness in IT (PIIT). A considerable amount of IS literature has demonstrated that PIIT is associated with IT adoption and usage $[1,17,20]$. PIIT represents "the willingness of an individual to try out any new information technology" [1]. Within the entrepreneurship context, Schumpeter's definition of entrepreneurship addresses economic factors as well as emphasizing on innovation [50]. According to Schumpeter, entrepreneurship is a function of innovation opportunities, and entrepreneurs are innovators who create something new into economy. From IS perspective, entrepreneurs highly depend on technological innovation to create new technological enterprises and new technologies [17, 20]. Some well- empirical studies have tested the relationship between PIIT and individual's behavior providing evidence of a significant relationship [1, 17, 20]. For instance, Chen (2014) shows that PIIT has a direct and indirect influence on ESE and IT entrepreneurial intention [17]. A result confirmed by others such as Dutta et al, (2015) who show that PIIT act as key drivers, and the impact of PIIT on entrepreneurial intention is fully mediated through perceived feasibility. Perceived feasibility, also referred to as entrepreneurial self-efficacy in many studies [20]. In the present study, it is reasonable to view that female entrepreneurship at an IT level is driven by many factors including innovation and PIIT. As discussed earlier, scholars found that compared to men, women's perception of their entrepreneurial skills have been more reduced frequently, regardless their real skills [45, 57]. Therefore, it is reasonable to expect that PIIT could play a critical role in the development of entrepreneurial self-efficacy. This proposition confirms previous studies showing that individual with high PIIT will improve his/her ability, motivate him/her to incubate technological innovation and look for ways it could be deployed to transform technology innovation into market opportunity $[5,20]$. Thus, the following hypothesis is proposed:

Hypothesis 3a: Personal innovativeness with IT positively influences entrepreneurial self-efficacy of women.

3.1.5 Related Knowledge and Experience in Technology. Related knowledge and experience (RKE) considered as important in the development of
IT entrepreneurial intention. Computer knowledge refers to the self-perception of the extent of knowledge regarding the use of computers across different application domains. A prior computing experience is defined as the frequency of using computers across different tasks and purposes. Both factors reflect individual's direct experience with computers from the past and the present [26]. An individual with a high level of RKE will enable him/her to connect the previous relevant knowledge with the new knowledge, which in turn helps to identify and develop opportunities at the intersection [20, 41]. From this viewpoint, Dutta, et al, (2015) were able to demonstrate that RKE of the entrepreneur act as key drivers, which influence the development of entrepreneurial intentions in technological industries. Following the social cognitive theory, RKE provides the most important source of information for the development of entrepreneurial self-efficacy. Therefore, it is more reasonable to assume that RKE is an antecedent to entrepreneurial self-efficacy, which in turn influences women's IT entrepreneurial intention. Thus, the following hypothesis is proposed:

Hypothesis 3b: Related knowledge and experience positively influence entrepreneurial selfefficacy of Saudi women.

Based on the above hypotheses, the initial research model has been developed as shown in Figure 1. As illustrated in the model, socio-individual factors have a direct influence on IT entrepreneurial intention (gender stereotypes has also indirect influence via social norms), and technological factors have indirect influence via entrepreneurial selfefficacy.

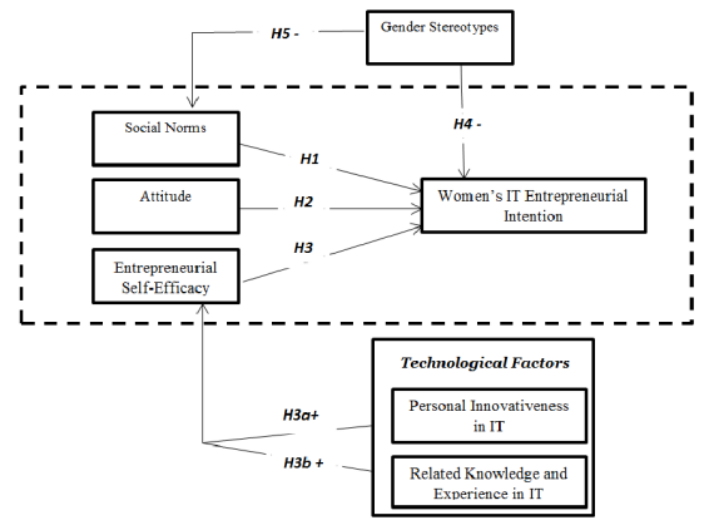

Figure 1: Initial model of women's IT entrepreneurial intention

\section{Research Methodology}


This study utilizes survey methodology supported by qualitative methods. Survey method will enable us to get a numeric or quantitative trends description of population's opinions and attitudes based on studying a sample of this population [18]. The survey approach is a widely used method in IS and female entrepreneurship research in general and more specific when considering entrepreneurial intentions $[16,17,19,20,23,49$, 51] among others. Consequently, considering the theoretical approach, the nature of the research questions as well as a large number of potential respondents in the sample size, quantitative method and specifically survey approach is considered to be the primary method for data collection. Stage two employs a qualitative method using interviews. Data collected from interviews will be interpreted to validate the quantitative investigation.

The kind of a population is expected to provide a best chance for exploring IT entrepreneurial intentions and it would provide the needed variance for this study. Hence, it is concluded that the study would be targeted at female level in two different categories of population, who would differ on levels of knowledge, experience, and perception. This includes female university students (including undergraduate in their last years and graduate university students) majoring in different disciplines including but not limited to students majoring in IT and other related areas as well as subjects related to business and management. Furthermore, the sample will include nascent entrepreneurs who are not entrepreneurs yet, but are pondering on it and in the process of starting a business.

With regard to the sample of students, there are basic reasons for this selection. Firstly, university students' samples have been widely used in entrepreneurship research especially when considering entrepreneurial intentions as the student will make a professional career choice and decision imminently after, and often before, graduation [9, 20]. Also, according to Sexton and Bowman (1986), the entrepreneurship students did not differ in a significant way from business owners in terms of conformity, energy level, interpersonal affect, social ability and risk aversion [19]. Similarity, Chen (20132014) stated that university students are welleducated and technologically savvy and many university students are interested in exploring business in the technology sector. Other authors show that university students are a dynamic segment of the population and, in the information age, they reflect the main source of entrepreneurial talent [19]. Along the same lines, Reynolds et al. (2002), argue that university graduates in the 25-34 years age range are the segment of the population with empirically a higher entrepreneurial probability [38, 47, 49]. Given all these reasons, it is reasonable to consider female students as a main target of the sample and would be more effective for this study.

Surveys will be distributed under the auspices of selected large, public universities and entrepreneurship programs in Saudi Arabia. After the completed surveys are received, arrangements will be made for interviews. In order to confirm the finding of the quantitative study accurately, it is important to match the sampling frame of the population of the qualitative study with that of the quantitative study. Interviews will be around 20 participants of female nascent entrepreneurs (including graduates, employed, unemployed women) under the auspices of the selected entrepreneurship programs.

\section{Conclusion}

This study aims to make a significant contribution to women's IT entrepreneurs in general and Saudi women entrepreneurs in particular by answering research questions, as yet unaddressed. Consequently, the initial model has been proposed to examine the selected constructs. The result of this study will provide a further understanding of the dynamics involved in the decision-making process concerning women in technological entrepreneurship in Saudi Arabia. Practical implications of this study aim to provide knowledge and means for policymakers for designing policies that promote female technology-based entrepreneurship. Finally, this study is also expected to contribute to the literature of knowledge creation. Universities play a critical role in the production of knowledge needed for entrepreneurship [43]. It contributes to enhance women's knowledge, which can significantly increase IT entrepreneurial intention. Hence, a number of practical implications could be communicated to researchers and educators to advance knowledge to improve entrepreneurship education, programs and activities in these universities in an effort to increase the female entrepreneurship culture and explore different kinds of entrepreneurial activities.

\section{References}

[1] R. Agarwal and J. Prasad, "A conceptual and operational definition of personal innovativeness in the domain of information technology," Information systems research, vol. 9, pp. 204215, 1998. 
[2] H. Ahl, "Why research on women entrepreneurs needs new directions," Entrepreneurship Theory and Practice, vol. 30, pp. 595-621, 2006.

[3] M. K. Ahuja and J. B. Thatcher, "Moving beyond intentions and toward the theory of trying: effects of work environment and gender on postadoption information technology use," MIS quarterly, vol. 29, pp. 427-459, 2005.

[4] I. Ajzen, "The theory of planned behavior," Organizational behavior and human decision processes, vol. 50, pp. 179-211, 1991.

[5] A. Aleidi and D. Chandran, "Does Institutional Environment Promote Women's IT Entrepreneurial Intention in Saudi Arabia? Technological and Institutional Perspectives," PACIS 2017 Proceedings. 208., 2017.

[6] W. N. Almobaireek and T. S. Manolova, "Entrepreneurial motivations among female university youth in Saudi Arabia," Journal of Business Economics and Management, vol. 14, pp. S56-S75, 2013.

[7] A. L. Anna, G. N. Chandler, E. Jansen, and N. P. Mero, "Women business owners in traditional and non-traditional industries," Journal of Business venturing, vol. 15, pp. 279-303, 2000.

[8] M. J. Austin and M. M. Nauta, "Entrepreneurial Role-Model Exposure, Self-Efficacy, and Women's Entrepreneurial Intentions," Journal of Career Development, p. 0894845315597475, 2015.

[9] E. Autio, R. H. Keeley, M. Klofsten, G. GC Parker, and M. Hay, "Entrepreneurial intent among students in Scandinavia and in the USA," Enterprise and Innovation Management Studies, vol. 2, pp. 145-160, 2001.

[10] S. S. Babalola, "Women entrepreneurial innovative behaviour: The role of psychological capital," International Journal of Business and Management, vol. 4, p. 184, 2009.

[11] A. Bandura, Social foundations of thought and action: A social cognitive theory: Prentice-Hall, Inc, 1986.

[12] J. R. Baum, E. A. Locke, and K. G. Smith, "A multidimensional model of venture growth," Academy of management journal, vol. 44, pp. 292-303, 2001.

[13] B. Bird and C. Brush, "A gendered perspective on organizational creation," Entrepreneurship theory and practice, vol. 26, pp. 41-66, 2002.

[14] C. Camelo-Ordaz, J. P. Diánez-González, and J. Ruiz-Navarro, "The influence of gender on entrepreneurial intention: The mediating role of perceptual factors," BRQ Business Research Quarterly, 2016.

[15] C. C. Chen, P. G. Greene, and A. Crick, "Does entrepreneurial self-efficacy distinguish entrepreneurs from managers?," Journal of business venturing, vol. 13, pp. 295-316, 1998.

[16] L. Chen, "IT entrepreneurial intention among college students: An empirical study," Journal of
Information Systems Education, vol. 24, p. 233, 2013.

[17] L. Chen, "Understanding it Entrepreneurial Intention: An Information Systems View," Journal of Computer Information Systems, vol. 55, pp. 2-12, 2014.

[18] J. W. Creswell, "Research design: Qualitative, quantitative, and mixed methods design," Sage, London, 2003.

[19] M. C. Díaz-García and J. Jiménez-Moreno, "Entrepreneurial intention: the role of gender," International Entrepreneurship and Management Journal, vol. 6, pp. 261-283, 2010.

[20] D. K. Dutta, K. L. Gwebu, and J. Wang, "Personal innovativeness in technology, related knowledge and experience, and entrepreneurial intentions in emerging technology industries: a process of causation or effectuation?," International Entrepreneurship and Management Journal, vol. 11, pp. 529-555, 2015.

[21] S. R. Ezzedeen and J. Zikic, "Entrepreneurial experiences of women in Canadian high technology," International Journal of Gender and Entrepreneurship, vol. 4, pp. 44-64, 2012.

[22] D. Gefen and D. W. Straub, "Gender differences in the perception and use of e-mail: An extension to the technology acceptance model," MIS quarterly, pp. 389-400, 1997.

[23] V. K. Gupta, D. B. Turban, S. A. Wasti, and A. Sikdar, "The role of gender stereotypes in perceptions of entrepreneurs and intentions to become an entrepreneur," Entrepreneurship theory and practice, vol. 33, pp. 397-417, 2009.

[24] A. Hampton, S. Cooper, and P. Mcgowan, "Female entrepreneurial networks and networking activity in technology-based ventures an exploratory study," International Small Business Journal, vol. 27, pp. 193-214, 2009.

[25] A. Hampton, P. McGowan, and S. Cooper, "Developing quality in female high-technology entrepreneurs' networks," International Journal of Entrepreneurial Behavior \& Research, vol. 17, pp. 588-606, 2011.

[26] J. He and L. A. Freeman, "Understanding the formation of general computer self-efficacy," Communications of the Association for Information Systems, vol. 26, p. 12, 2010.

[27] M. E. Heilman, "Sex bias in work settings: The lack of fit model," Research in organizational behavior, 1983.

[28] C. Henry, L. Treanor, G. L. Sweida, and R. J. Reichard, "Gender stereotyping effects on entrepreneurial self-efficacy and high-growth entrepreneurial intention," Journal of Small Business and Enterprise Development, vol. 20, pp. 296-313, 2013.

[29] G. Hofstede, "Masculinity/feminity as a dimension of culture," 1998.

[30] M. Igbaria, S. Parasuraman, and J. H. Greenhaus, "Status report on women and men in the IT 
workplace," Information Systems Management, vol. 14, pp. 44-53, 1997.

[31] D. J. Kelley, S. Singer, and M. Herrington, "The global entrepreneurship monitor," 2011 Global Report, GEM 2011, vol. 7, 2012.

[32] K. o. S. A. M. o. E. a. P. Kingdom, "Brief Report on the Ninth Develoment Plan ", ed, 2010-2014.

[33] P. Koellinger, M. Minniti, and C. Schade, "Gender Differences in Entrepreneurial Propensity*," Oxford bulletin of economics and statistics, vol. 75, pp. 213-234, 2013.

[34] L. Kolvereid, "Prediction of employment status choice intentions," Entrepreneurship: Theory and Practice, vol. 21, pp. 47-58, 1996.

[35] N. F. Krueger, M. D. Reilly, and A. L. Carsrud, "Competing models of entrepreneurial intentions," Journal of business venturing, vol. 15, pp. 411-432, 2000.

[36] N. Langowitz and M. Minniti, "The entrepreneurial propensity of women," Entrepreneurship theory and practice, vol. 31, pp. 341-364, 2007.

[37] S. M. Lee and L. Chen, "The impact of flow on online consumer behavior," Journal of Computer Information Systems, vol. 50, pp. 1-10, 2010.

[38] F. Liñán, J. C. Rodríguez-Cohard, and J. M. Rueda-Cantuche, "Factors affecting entrepreneurial intention levels: a role for education," International Entrepreneurship and Management Journal, vol. 7, pp. 195-218, 2011.

[39] S. Marlow and M. McAdam, "Analyzing the influence of gender upon high-technology venturing within the context of business incubation," Entrepreneurship Theory and Practice, vol. 36, pp. 655-676, 2012.

[40] S. Marlow and D. Patton, "All credit to men? Entrepreneurship, finance, and gender," Entrepreneurship theory and practice, vol. 29, pp. 717-735, 2005.

[41] M. R. Marvel and G. T. Lumpkin, "Technology entrepreneurs' human capital and its effects on innovation radicalness," Entrepreneurship Theory and Practice, vol. 31, pp. 807-828, 2007.

[42] H. Mayer, "Economic trends and location patterns of women high-tech entrepreneurs," Frontiers of entrepreneurship research, vol. 26, p. 1, 2006.

[43] J. Mitra, Y. A. Abubakar, and M. Sagagi, "Knowledge creation and human capital for development: the role of graduate entrepreneurship," Education+ Training, vol. 53, pp. 462-479, 2011.

[44] S. P. Nichols and N. E. Armstrong, "Engineering entrepreneurship: does entrepreneurship have a role in engineering education?," Antennas and Propagation Magazine, IEEE, vol. 45, pp. 134138, 2003.

[45] M. Noguera, C. Alvarez, and D. Urbano, "Sociocultural factors and female entrepreneurship," International Entrepreneurship and Management Journal, vol. 9, pp. 183-197, 2013.
[46] J. Palmer, M. Griswold, V. Eidson, and P. Wiewel, "ENTREPRENEURIAL INTENTIONS OF MALE AND FEMALE UNIVERSITY STUDENTS," International Journal of Business \& Public Administration, vol. 12, 2015.

[47] P. Reynolds, S. Camp, W. Bygrave, E. Autio, and M. Hay, "GEM Global Entrepreneurship Report, 2001. Summary Report, 1-126," ed, 2002.

[48] A. Rubio-Bañón and N. Esteban-Lloret, "Cultural factors and gender role in female entrepreneurship," Suma de Negocios, 2016.

[49] F. J. Santos, F. Liñán, and M. A. Roomi, "A cognitive attempt to understanding female entrepreneurial potential," 2010.

[50] J. A. Schumpeter, The theory of economic development: An inquiry into profits, capital, credit, interest, and the business cycle vol. 55: Transaction publishers, 1934.

[51] R. S. Shinnar, O. Giacomin, and F. Janssen, "Entrepreneurial perceptions and intentions: The role of gender and culture," Entrepreneurship Theory and Practice, vol. 36, pp. 465-493, 2012.

[52] R. L. Thompson, C. A. Higgins, and J. M. Howell, "Personal computing: toward a conceptual model of utilization," MIS quarterly, pp. 125-143, 1991.

[53] V. Venkatesh and M. G. Morris, "Why don't men ever stop to ask for directions? Gender, social influence, and their role in technology acceptance and usage behavior," MIS quarterly, pp. 115-139, 2000.

[54] S. Vision 2030, "Vision 2030 ", ed, 2016.

[55] J. Wagner, "What a difference a Y makes-female and male nascent entrepreneurs in Germany," Small Business Economics, vol. 28, pp. 1-21, 2007.

[56] F. Welter, D. Smallbone, N. Isakova, and E. Aculai, "10. The role of gender for entrepreneurship in a transition context," Entrepreneurship, Competitiveness and Local Development: Frontiers in European Entrepreneurship Research, p. 223, 2007.

[57] F. Wilson, J. Kickul, and D. Marlino, "Gender, entrepreneurial Self-Efficacy, and entrepreneurial career intentions," Entrepreneurship theory and practice, vol. 31, 2007.

[58] A. Yousuf Danish and H. Lawton Smith, "Female entrepreneurship in Saudi Arabia: Opportunities and challenges," International Journal of Gender and Entrepreneurship, vol. 4, pp. 216-235, 2012.

[59] H. Zhao, S. E. Seibert, and G. E. Hills, "The mediating role of self-efficacy in the development of entrepreneurial intentions," Journal of applied psychology, vol. 90, p. 1265, 2005. 